\title{
Três histórias: velhice feminina, agência e reflexividade em contextos de convivências intergeracionais ${ }^{1}$
}

\author{
Cristiane Leal Rodrigues Soares \\ Doutora em Sociologia pela Universidade Federal da Paraíba \\ Professora da Universidade Federal da Paraíba \\ João Pessoa, Paraíba, Brasil \\ cristiane.30@hotmail.com
}

\begin{abstract}
Resumo Neste trabalho procuramos refletir sobre a categoria velhice feminina, relacionando-a com os conceitos de agência e de reflexividade de Anthony Giddens. Mais precisamente, abordamos possibilidades de convivências familiares em contextos intergeracionais em que se incluem mulheres participantes de grupos que agenciam o envelhecimento contemporâneo. Para tanto, selecionamos narrativas de vida de três senhoras, de idade entre 62 e 70 anos, que integraram um grupo de idosas de uma pesquisa de doutorado em Sociologia realizada na Universidade Federal da Paraíba. Os métodos de investigação consistiram na observação participante e em entrevistas do tipo história de vida em que se fazem os seguintes questionamentos: como essas mulheres lidam, especialmente com filhos e netos, com as perspectivas das diferentes propostas de envelhecimento com as quais se envolvem em seu cotidiano? Que mudanças nas relações familiares podem ser apontadas com as interferências das ideologias disseminadas nos grupos de idosos pela Igreja e pela saúde pública? Percebemos essas senhoras como agentes que monitoram continuamente os fluxos de informações aos quais têm acesso. Elas reinventam suas experiências de velhice no diálogo entre os referenciais extra e intrafamiliares, fazendo escolhas que primam pela convivência familiar e priorizam as relações extrafamiliares.
\end{abstract}

Palavras-chave: velhice feminina, agência, reflexividade, relações intrageracionais, relações intergeracionais.

\section{Introdução}

$\mathrm{O}$ estudos produzidos sobre velhice nas três últimas décadas, sobretudo pela Antropologia e pela Sociologia, têm convergido na tentativa da desconstrução da velhice como uma experiência homogênea. Esses estudos revelam que, se por um lado, envelhecer é um processo pelo qual todos temos de passar, por outro, ele é diferente para cada pessoa, segundo o grupo social, o sexo e o sistema simbólico a que pertença. Não é simplesmente o avanço da idade, ou a idade cronológica, que encerra o estado da velhice. Segundo Debert (1999), os recortes de idade e as práticas características de cada fase da vida são

1. O título e a estrutura deste trabalho procuram fazer uma homenagem à antropóloga Mónica Franch, pelas inspirações alcançadas com as leituras de seus trabalhos e pela contribuição à pesquisa de tese da qual este texto resulta. Agradecimentos também a Parry Scott, Teresa Cristina Mattos e, de forma especial, a Tereza Queiroz. 
construções históricas e sociais e comportam ilimitadas representações. A padronização das experiências etárias, fortemente associada à modernidade, deu lugar a novas e diversas formas individuais de vivência e apresentação da idade. Isso se relaciona com o que Andréa Alves (2006) comenta sobre a individualização das idades, um aspecto, segundo ela, resultante do processo maior de individualização vivenciado pela sociedade moderno-contemporânea.

Assistimos, nos últimos anos, a um avanço considerável da representatividade numérica dos idosos na população brasileira. O ponto de vista demográfico e sua recorrente divulgação pela mídia chamam a atenção da sociedade para o processo de envelhecimento em curso. No entanto, abreviar as transformações sociais às mudanças demográficas pelas quais atravessamos nos impediria de conhecer um conjunto de questões que, ao longo dos últimos anos, tem sido significativo para a compreensão das mudanças culturais em torno da velhice e do envelhecimento em nossa sociedade. Nesses anos, vários estudos socioculturais têm procurado desvendar os múltiplos aspectos do envelhecimento populacional e, em especial, do envelhecimento feminino, com temáticas de maior recorrência à sociabilidade, às relações geracionais, às políticas sociais da velhice, ao sistema de seguridade e previdência, entre outras. ${ }^{2}$ Apesar das diferenças em suas abordagens, tais estudos têm apresentado uma tendência de revisita aos estereótipos associados à velhice $\mathrm{e}$ às fronteiras que delimitam essa etapa da vida, apontando para seu contínuo deslocamento e para suas variações segundo o sistema simbólico de cada cultura. Esses trabalhos visam à compreensão das experiências humanas, dos significados conferidos à velhice e ao envelhecimento, assim como das novas possibilidades de construções de outras classificações etárias, tais como meia idade, terceira idade, melhor idade, entre outras denominações.

Essas novas classificações, como observa Peixoto (2007), não são simples substitutos para o termo velhice, pois podem também representar etapas intermediárias de envelhecimento. São como "interlúdios maduros", como observa Debert (1999), entre a idade adulta e a velhice. Esta última, como estigma, não está necessariamente ligada à idade cronológica. O termo idoso, no Brasil, assim como na Europa, surgiu como uma forma mais respeitosa para designar as pessoas de mais idade. Já a expressão terceira idade, também proveniente da Europa, surgiu para designar uma parcela desse grupo, os "jovens - velhos", os aposentados dinâmicos, a fase da vida na qual a ociosidade simboliza a prática de novas atividades sob o signo do dinamismo e da ética da autogestão.

A expressão terceira idade ${ }^{3}$ veio agregada a uma multiplicidade de atores, cuja função específica foi a de tratar a velhice, fazendo-a adquirir maior visibilidade, especialmente como campo de mercado. Segundo Debert (1999), tal expressão diz respeito à responsabilização do indivíduo por seu próprio cuidado e bem-estar, correspondendo a um processo de reprivatização da velhice. Ou seja, com o termo, a velhice passou a ser compreendida a partir do plano das opções individuais e a ser pensada como período de lazer, de desenvolvimento das potencialidades e das realizações até então inalcançadas. A autora ressalta que os estereótipos de solidão e abandono, que caracterizariam a experiência de envelhecimento, têm sido progressivamente substituídos pela imagem dos idosos como seres ativos, como seres capazes de desenvolver novas formas de sociabilidade, de reciclar identidades anteriores e de redefinir as relações familiares. Os múltiplos programas para a terceira idade têm apresentado-se como forma privilegiada de oportunidades de ampliação do círculo de amizades, para a criação de novos espaços de ação, e, portanto, de novas experiências da velhice.

Assim, do mesmo modo como não são padronizadas as experiências da velhice, também não o são os comportamentos dos idosos diante das múltiplas estruturas que, de forma geral, envolvem esse grupo etário, tais como grupos de terceira idade ligados às equipes de saúde, grupos religiosos, academias da terceira idade, entre outros. As transformações processadas em torno da velhice são também resultantes das ações dos idosos em relação a essas estruturas, ou seja, nesses processos de reinvenção da velhice, os idosos são, por um lado, influenciados pelos diferentes discursos - da terceira idade, do envelhecimento ativo, entre outros - que circulam nestas estruturas e que trazem em si uma comunhão de códigos culturais relativos ao envelhecimento na contemporaneidade. Mas, por outro lado, os idosos são também, eles próprios, agentes (Giddens, 2003) com capacidade reflexiva para filtrar informações e fazer escolhas próprias, individualizadas, sobre quais atitudes empreender nessa fase de suas vidas.

Para Giddens (1991), a reflexividade - característica da ação humana e que na alta modernidade chega a condições mais amplas - "consiste no fato de que as práticas sociais são constantemente examinadas e reformadas à luz de informação renovada sobre estas próprias práticas, alterando assim constitutivamen-

2. Entre os estudos nacionais, destaco os desenvolvidos por Guita Grin Debert (1999), Myriam Lins de Barros (2007), Andrea Alves (2006), Clarice Peixoto (2007), Alda Brito da Motta $(2007,2011)$ e Júlio Simões (2007).

3. Conforme ensina Debert (1999, p. 138), "a expressão originou-se na França, com a implantação, nos anos 70, das 'Universités du Troisiéme Age'" $^{\prime \prime}$ 
te seu caráter" (p. 45). É esse caráter reflexivo, com base no conhecimento renovado - formulado não somente nos espaços de vivências dos sujeitos, mas para além de suas imediações locais, em múltiplas instituições, como universidades, escolas, Estado, espaços de saúde, igrejas, entre outras - que primordialmente orienta as ações na vida moderna, inclusive entre os idosos, diferentemente dos contextos tradicionais, em que os costumes tinham esse papel.

A ideia de agência aqui desenvolvida encontra na teoria da estruturação, de Giddens, o seu pilar. Refere-se à capacidade que as pessoas possuem de realizar escolhas, tomar certas atitudes em detrimento de outras possíveis. Diz respeito aos eventos conduzidos pelas interferências do indivíduo no mundo em que vive, a partir das múltiplas possibilidades de escolhas - sobre o que comer, usar, fazer, com quem se relacionar etc. - existentes no cotidiano contemporâneo. Esses indivíduos, como agentes, são sempre reflexivos e podem alterar suas condutas a todo momento, o que, por sua vez, designa um fluxo contínuo de mudança social. Ser um agente é ter a capacidade de "criar uma diferença", significa ser capaz de intervir no mundo ou de abster-se disso, exibindo assim possibilidades de poder, entendidas como "capacidade transformadora” (Giddens, 2003, p. 17).

A principal categoria de análise deste trabalho é o envelhecimento feminino. No entanto, procuramos discuti-la em diálogo com os conceitos de agência e reflexividade propostos por Giddens em sua análise sobre a alta modernidade. É a partir das considerações do autor sobre reflexividade e agência que procuramos refletir, neste trabalho, sobre as relações intergeracionais desenvolvidas por mulheres idosas com seus familiares, estritamente filhos e netos. Compreendendo-as como agentes, procuramos perceber as influências que as estruturas sociais - especialmente as que dizem respeito à velhice - exercem sobre suas experiências enquanto idosas que fazem parte de conformações familiares marcadamente caracterizadas pelo convívio intergeracional. $\mathrm{O}$ trabalho aborda ainda possibilidades de convivência intergeracional em que se incluem mulheres idosas que, apesar de influenciadas, em alguma medida, por estruturas agenciadoras do envelhecimento contemporâneo, são também, elas mesmas, responsáveis não somente pelas próprias experiências de velhice, como pelas convivências intergeracionais por elas experimentadas nessa etapa de suas vidas.

Entre os questionamentos que nortearam o trabalho, destacamos inicialmente: como essas mulheres lidam, em meio às suas relações familiares, especialmente entre filhos e netos, com as perspectivas das diferentes propostas de envelhecimento com as quais se envolvem em seu cotidiano? Que mudanças ou permanências nas relações familiares podem ser apontadas com as interferências das ideologias disseminadas nos grupos de idosos formados por estruturas como a Igreja e a saúde pública?

Os elementos empíricos deste trabalho foram qualitativamente coletados. Utilizamos primordialmente o recurso da observação participante e entrevistas do tipo histórias de vida, para reunir o material que fundamentou as reflexões aqui apresentadas. Para este artigo, foram selecionadas as narrativas de três senhoras - dona Ana, dona Rita e dona Rosa ${ }^{4}$ - residentes em Bancários, um dos bairros que abriga moradores do segmento médio da cidade de João Pessoa, capital paraibana.

\section{Primeira história}

Dona Ana: Aí, quando a gente veio pra cá, e eu comecei a sair com minhas amigas... na comunidade, tem um bocado de gente que é advogada, dentista, psicóloga, pessoas que têm compreensão das coisas, né? E vai ensinando a gente. Até o médico mesmo. Quando eu vou, ele diz: - "Deixa esse filho! Ele já está velho!” Eu fui me abrindo, largando aqui em casa. Hoje, quando ele chega, ele mesmo vai no fogão, frita um ovo, passa manteiga no pão e come, e vai dormir sem falar nada. Porque antes eu me levantava e ia preparar tudo pra ele. Agora todo mundo ajuda aqui, as coisas não são como antigamente mais não, agora todo mundo ajuda! Porque en achava que tinha que fazer tudo em casa, sozinha... eu abria mão da minha vida para fazer tudo para meus filhos...e olhe que muitas vezes ninguém reconhece. Hoje não, eu faço primeiro minhas coisas, depois o tempo que sobra eu cuido das coisas de casa.

$\mathrm{Na}$ ocasião em que foi entrevistada, dona Ana tinha 68 anos e morava num apartamento de aproximadamente $90 \mathrm{~m}^{2}$, juntamente com dois filhos solteiros e dois netos já adultos. Viúva há mais de 30 anos, dona Ana nunca firmou um novo relacionamento, pois, após a viuvez, devotou sua vida exclusivamente para a família e para seu sustento. A maior parte de sua história de vida é marcada por essa dedicação e pela valorização da família como veículo de realização pessoal. O trecho acima em destaque, no entanto, traz para a narrativa transformações consideráveis em suas relações familiares e, em especial, com seu filho.

Pode-se observar que, por meio das influências de um conjunto de informações, especialmente vindas de pessoas a quem se credita confiança na alta modernidade por representar aquilo que Giddens (1991) chama de peritos - o médico, o psicólogo, o advogado, entre outros apontados em sua fala - dona 
Ana passa a rever suas práticas domésticas e seu modo de lidar com a família. Imbuída de uma "capacidade transformadora", essa senhora procura contribuir para que relações mais igualitárias sejam possíveis em sua família, ao mesmo tempo em que escolhe priorizar algumas de suas próprias atividades, nas quais encontra autossatisfação, para além daquelas desenvolvidas em casa.

De acordo com dona Ana, frequentadora assídua do Projeto Vida Saudável, desenvolvido na Praça da $\mathrm{Paz}^{5}$ por agentes de saúde ligados à prefeitura da cidade, oferecendo exercícios físicos e programações lúdicas como forma de integração especialmente para mulheres idosas, as relações ali estabelecidas se mostraram intensamente significativas, por representarem aberturas para o público, ampliação dos "outros significativos", para os cuidados corporais, para as sociabilidades intrageracionais. Neste grupo, o discurso prevalecente é o do corpo ativo, saudável e autônomo e da ampliação das sociabilidades, ideias estas próprias da ideologia da terceira idade, fomentada, neste caso, especialmente pelos "sistemas peritos" da saúde envolvidos no projeto citado.

Dona Ana: A primeira coisa que faço todos os dias é ir para a praça fazer meus exercícios, respirar o ar livre, fazer meus alongamentos com as professoras, verificar minha pressão, encontrar com minhas colegas, dar risadas. Isso, pra mim, é uma terapia também. Depois, tô pronta pra qualquer coisa. (...) Cuido muito do meu corpo, da minha saúde, porque não quero ficar como uma velha dando trabalho a ninguém. Não quero ficar na dependência de ninguém; também quero poder sair, poder pegar um ônibus, e, principalmente, poder aproveitar minha vida com minhas colegas. (...) Estou beirando os setenta anos, mas quero me sentir jovem, disposta, alegre e poder viver feliz por muito tempo, se Deus assim permitir. (...) Essas atividades que a gente da comunidade faz na praça foi a melhor coisa do mundo pra nós, idosas, porque nos anima, sabe? Levanta a autoestima, a gente fica outra, alegre, de bem com a vida, além do que ajuda em nossa saúde.

$\mathrm{Na}$ fala de dona Ana é possível compreender que, para ela, os cuidados corporais para a manutenção da saúde e da disposição apresentaram múltiplos significados. De um lado, aproximam-se da perspectiva de Featherstone (1994), para quem a concepção de autopreservação do corpo associa-se "à noção de que o corpo é um veículo de prazer e de autoexpressão" (p. 170). Por outro lado, tais cuidados corporais também são executados mediante a compreensão do corpo como instrumento relacional, tanto na família como extrafamiliar, já que a participação social depende de um corpo autônomo, dinâmico e disposto.
Também se destaca, na fala dessa senhora, a perspectiva da juventude como valor. A partir do referido trecho, pode-se também pensar a respeito da idade cronológica, que, apesar de conformar importante dimensão das experiências individuais e na organização social, pode ser considerada um "clichê natural" (Featherstone; Hepworth, 2000, p. 115). Isto porque, na verdade, a plasticidade cultural que vivenciamos tem permitido um embaralhamento de experiências, a ponto de reconhecermos a "juventude" não somente como uma fase da vida, mas também como valor (Debert, 1999) que pode ser associado a qualquer etapa, inclusive entre aquelas em que a idade esteja avançada. Dona Ana nega a velhice reclusa e procura conter o declínio do corpo, adiando como pode a perda da autonomia e desenvolvendo com isso um envelhecimento centrado na busca contínua da autoestima e autossatisfação. Ao dizer que "a gente fica outra" mediante a participação nessas atividades, essa senhora destaca a busca pela superação de possíveis qualidades negativas da velhice e o desenvolvimento de vivências fundadas na liberdade, no companheirismo e na integração social.

Dona Ana: Depois que eu vim pra cá, pra Bancários, foi que en comecei a viver, a desfrutar das coisas boas da vida. A ter minha liberdade (...). Foi aqui que minha vida mudou da água pro vinho. (...) Aqui, junto com minhas amigas da academia da Praça e da comunidade, que são da minha idade, aprendi que posso ser mais extrovertida. Eu era muito retraída, fechada mesmo, e isso me fazia mal. Eu quase não sorria, tinha vergonha de tudo. Hoje não, sou mais solta, mais feliz. Tenho amigas que gostam das mesmas coisas que eu e que são companheiras, sabe?

Em seu relato, dona Ana evidencia os efeitos da ampliação de seus outros significativos sobre suas formas de viver e de ser. Tais transformações podem ser compreendidas como processos de construção de si, possíveis também na velhice. Em parte, essas transformações mostram uma espécie de superação de atributos vistos como negativos, revelando a importância do convívio intrageracional para a apresentação de predicados positivos: ser mais alegre, mais extrovertida etc. Mas, para que essa superação seja constatada, ela tem de ser manifesta socialmente. Ela exige que as performances dos indivíduos, no desenrolar de suas interações sociais, situem-se fora de imagens negativas e sejam preferencialmente identificadas com qualidades culturalmente relacionadas à juventude e aos valores preponderantes da contemporaneidade, isto é, ao ethos do novo. Trata-se de "uma constelação de valores essencialmente morais, que norteia a visão 
de mundo prevalecente na realidade social" (Viegas; Gomes, 2007, p. 31).

Tais valores pressupõem inovação, mudança, produtividade, autonomia e independência, mas, além de tudo isso, envolvem fundamentalmente a participação e o envolvimento com a sociedade, além da ética da realização pessoal, disseminada especialmente entre os grupos de idosos por meio dos modelos de envelhecimento da Terceira Idade ou do Envelhecimento Ativo. Tais modelos difundem receitas sobre as melhores formas de viver a velhice, e, associando-se à mídia, aperfeiçoam a propagação positiva de suas propostas. Tudo isso se relaciona com a discussão que Giddens (1991) sobre as modificações observadas nas relações de confiança em nossa sociedade. Fundamentados nos sistemas peritos, especialmente no campo médico, os modelos da Terceira Idade e do Envelhecimento Ativo conquistam a confiança de seus adeptos.

Para Giddens (1991), as relações de confiança presentes na atualidade da vida social são profundamente modificadas se comparadas ao período tradicional, em que "a confiança era enfocada por conexões personalizadas no interior da comunidade local e das redes de parentesco" (p. 123). Contemporaneamente, os indivíduos encontram confiança especialmente nas "informações renovadas" dos mais diferentes profissionais. São constantemente levados ao monitoramento de suas ações e das ações dos demais, com base nas inúmeras informações a que têm acesso. Entre as idosas, isso não é diferente: elas também acionam recorrentemente aquilo que Giddens chama de monitoramento reflexivo de suas práticas.

O monitoramento reflexivo da atividade é uma característica crônica da ação cotidiana e envolve a conduta não apenas do indivíduo, mas também de outros. Quer dizer, os atores não só controlam e regulam continuamente o fluxo de suas atividades e esperam que outros façam o mesmo por sua própria conta, mas também monitoram rotineiramente aspectos sociais, físicos, dos contextos em que se movem. (Giddens, 2002, p. 6)

É por meio desse monitoramento que dona Ana procura selecionar práticas mais adequadas ao seu projeto de velhice, para suas condições materiais de vida e para continuar presente cotidianamente na rotina dos familiares com quem habita. Mediante sua capacidade reflexiva, faz escolhas e abraça, no cotidiano, atividades com as quais encontra identificação, sejam elas baseadas em modelos mais tradicionais de comportamento ou em estilos mais modernos. Tal como observa Giddens (2002), "o eu, como os contextos institucionais mais amplos em que existe, tem que ser constituído reflexivamente" (p.
11). Ou seja, mesmo aderindo às inúmeras regras técnicas - de alimentação, desenvolvimento das sociabilidades, práticas de exercícios, entre outras - alcançadas no grupo da terceira idade que frequenta na Praça da Paz, dona Ana, mediante sua capacidade reflexiva, faz escolhas sobre o que comer, como se vestir, que ambientes frequentar, em que dias e horários se ausentar de casa, sempre pensando em desenvolver uma vida ativa, sociabilidades intrageracionais, mas sem perder de vista os laços intergeracionais e afetivos da família.

Dona Ana: Hoje faço minhas caminhadas, me alimento de forma saudável, saio muito, converso com as pessoas na rua, farreio com minhas amigas, tudo muito saudável. Não faço nada de errado, nada que ponha em risco minha própria saúde e que venha a envergonhar minha família.

Pesquisadora: O que, por exemplo, seria algo errado para a senhora?

Dona Ana: Assim, sempre fui mãezona e continuo sendo. Tem algumas mulheres que esquecem esse lado família, sabe? Pensam que porque estão viúvas ou separadas, não tem ninguém no mundo, parecem que voltaram ao passado. São assanhadas, assim, exageram, vestem roupas de garotinhas, querem ficar nas festas até o dia amanhecer. Algumas bebem muito, se embriagam, perdem a noção do limite. Eu não, não concordo com essas coisas. Me divirto muito, mas assim, de forma saudável. Saio, procuro ver a melhor roupa que combine com minha idade, não bebo mais do que devo. A gente pode se divertir, mas tem que manter a linha, né?

Essa senhora se apresenta como agente, pois é também, ela própria, sujeito responsável pela construção da ideia de velhice e dos valores que a orientam, assim como é ela igualmente quem interpreta e dá significado à própria situação nessa fase da vida. A adesão às formas de comportamento mais individualizadas, especialmente aquelas que traduzem as regras da terceira idade, da juventude como valor ou do envelhecimento ativo, não necessariamente eliminam as lógicas mais relacionais do caráter brasileiro, tão bem discutidas por DaMatta (1991).

Ao monitorar os fluxos de informações dos sistemas a que tem acesso, tanto extra como intrafamiliares, dona Ana procura gerenciar as esferas pessoal e relacional de sua vida, ponderando suas escolhas e comportamentos na perspectiva do que seria mais adequado em determinados momentos para manter melhores convivências possíveis, evitando desentendimentos na família, sem perder o espaço de autonomia conquistado. É com base na negociação que dona Ana tem procurado pautar suas relações intergeracionais. Assim como pontuam Henriques, Féres-Carneiro e Ramos (2011), para dona Ana, bem como 
para seus filhos e netos, "a relação entre pais e filhos adultos que coabitam põe em relevo o que faz sentido para ambas as partes, e as negociações se estabelecem em função das demandas cotidianas" (p. 534).

Dona Ana: O que tenho de mais precioso na minha vida é minha família. Todos são importantes pra mim, mas esses que moram comigo, né, a gente se apega mais. Mas eles sabem que eu já me dediquei muito pra eles. Agora chegou meu tempo de parar de me preocupar só com eles, só com eles, que antes era assim, eu não pensava em mim. Tenho que pensar em mim também, tenho que aproveitar minha vida, fazer tudo o que ainda não tive oportunidade. (...) Às vezes, eles me fazem raiva, mas eu acho bom morar com eles, porque eu tenho com quem conversar, tenho companhia em casa. Eu sei que quando eu for chegar vai ter alguém me esperando. Não gosto de ficar em casa sozinha. Pra mim, é bom ter eles por perto. Já tô ficando velha, né, e às vezes preciso de um médico, uma coisa, com alguém em casa é melhor. E pra eles também é bom. Deve ser, né, porque não pagam aluguel, têm sempre as coisinhas de casa em ordem. Eles também lucram morando aqui, e nisso todo mundo ganha. Aí agente vai se ajeitando daqui, dali, quando um tá emburrado, a gente vai com jeitinho, com calma e com amor tudo se resolve. Só que às vezes é difícil, viu? Mas até aqui tem dado certo.

Dona Ana, atualmente - diferentemente do passado, quando vivia exclusivamente para os cuidados dos filhos e da casa -, sente-se descompromissada dos afazeres domésticos exclusivos. As novas regras de serviços compartilhados, fundadas no estabelecimento de "direitos e deveres" negociados entre ela e seus filhos e netos, proporcionam-lhe abertura para vivências mais amplas e para a execução de atividades que lhe trazem satisfação, para além daquelas relacionadas ao ambiente doméstico, para "viver aquilo que não teve oportunidade". Mas, por outro lado, a perspectiva do envelhecimento corporal também a motiva a manter relações familiares baseadas na afetividade e na ajuda mútua. A possibilidade de fragilidade do corpo, no envelhecimento, aparece como marcador da necessidade de reciprocidades de cuidados na família, o que, por sua vez, funciona como garantia de suporte para o envelhecimento assistido. Entre as regras de convivências intergeracionais, prioriza-se como fundamental o apoio mútuo. Entre dona Ana e seus filhos, a relação de reciprocidade é marcante. Se, de um lado, ela lhes oferece auxílio material e ajuda nas tarefas domésticas, por outro, reivindica acompanhamento em caso de enfermidade, além de companhia e, sobretudo, respeito.

\section{Segunda história}

Rita: Essa coisa de dizer que a pessoa pode ser jovem na minha idade acho muito estranho, não dá pra mim não!

Quando entrevistada, Rita era uma jovem senhora de 62 anos. Morava num apartamento bem equipado, com dois filhos estudantes universitários. Recebia aposentadoria de aproximadamente 7 mil reais e era ela a responsável financeira pelos filhos. Foi economista de um órgão federal, onde atuou por mais de vinte anos. Separada há pelo menos dois anos, Rita ainda sofria com intervenções do ex-marido em sua privacidade. Sua biografia coloca em discussão as tendências mostradas em algumas pesquisas, ou seja, as mulheres dos segmentos médios e altos são mais individualizadas do que as mulheres do segmento popular.

Apesar de frequentar o grupo de idosos da Praça da Paz, assim como dona Ana, Rita não adere a grande parte dos valores compartilhados naquele grupo. Ela, que integra o segmento médio, mais individualizado, conforme Velho (2008), contesta a ideia da juvenilização na velhice, presente no modelo da terceira idade disseminado pelos educadores físicos da Praça, ainda que considere interessantes suas propostas de uma vida saudável.

Rita: Essa coisa de dizer que a pessoa pode ser jovem na minha idade acho muito estranho, não dá pra mim, não! O pessoal da terceira idade tem isso, né? Tudo bem que você seja um idoso saudável, com ânimo para viver, para tocar a vida, mas querer dar uma de cocotinha nessa idade é chegar ao ridículo. Eu não me passo pelo ridículo, acho que cada um tem que ser o que é, assumir o que é. A adolescência já passou, pronto, passou, vamos viver o que temos. Quero viver a minha idade e não o que passou. Quero ser uma mulher forte, ajudar meus filhos, meus netos, cuidar da minha casa e de mim, ter paz. Pra mim tá bom demais.

Para essa senhora, viver a velhice sem aderir aos aspectos de sua redefinição, a partir de práticas compreendidas como sendo próprias de outras fases da vida, não necessariamente implica um insucesso da experiência do envelhecimento. Para ela, a velhice pode ser assumida positivamente como ela própria se apresenta, destacando a "força" de que, nessa fase, ela é capaz de demonstrar, no sentido de "ajudar" filhos e netos, "cuidar da casa" e de si mesma.

Cuidar de si mesma, para Rita, envolve uma alimentação saudável, a prática de exercícios, o acompanhamento médico, e ainda cuidados com a aparência, especialmente com os cabelos, unhas e pele. Esses cuidados se traduzem, para essa senhora, em um tempo de dedicação para si mesma, a partir da escolha por práticas como frequentar salões de beleza, por exemplo, onde procura cortar e pintar os cabelos, fazer as 
unhas, depilar-se, fazer limpeza de pele, entre outros tratamentos estéticos, que funcionam como importantes recursos para o aumento da autoestima e para sua apresentação como uma senhora "conservada", e não "desleixada", ou seja, uma senhora que assume sua idade, mas que prima por uma boa apresentação dela mesma.

Rita: Uma coisa que eu gosto é de ir pra o salão, assim pintar meus cabelos, fazer minhas unhas, isso eu sempre gostei. Retoco a pintura todo mês para evitar os brancos, gosto de manter minhas unhas feitas, dar um ar de higiene, de cuidado próprio. Não quero parecer uma pessoa desleixada. Não é porque estou envelhecendo que vou deixar isso acontecer, sou uma senhora conservada. Tiro sempre esse tempo pra mim, acho isso importante. Em casa, friso meu cabelo pra que ele fique arrumado quando vou sair. Vaidosa, assim, de extremo, nunca fui, mas não ando jogada, não.

Rita identifica-se com rotinas mais caseiras, dedicadas aos cuidados com a casa, aos bordados e, especialmente, à leitura. Define-se como uma mulher intelectualizada; gosta de literatura brasileira e de conhecer, por meio dos livros que adquire com frequência, a história de diferentes países.

Rita: Gostaria de ser muito uma pesquisadora. Talvez historiadora. Gosto muito de ler, de conhecer outras culturas, sou fascinada. Eu estudo muito a História Ocidental, mas o Oriente é simplesmente fantástico. Acho que por ser diferente de nós. Leio muito, sempre gostei de ler. Não sou uma pessoa leiga. Eu prefiro ficar em casa lendo do que sair por aí.

Essa atitude marca uma diferença interessante em relação às recomendações da terceira idade, sugeridas pelo grupo de idosos do qual faz parte, ou ao menos aquelas que dizem respeito às práticas das sociabilidades. Nesse aspecto, no caso de Rita visualiza-se a agência, a partir de sua capacidade de recriar, de exercer, num movimento reflexivo, uma seleção intencional do que considera adequado ao seu cotidiano. Por sua vez, ao agir de tal modo, Rita também reelabora as propriedades estruturais do grupo de idosos em que se insere, imprimindo ao modelo de envelhecimento o gosto pela leitura no espaço doméstico. Ou seja, se, por um lado, a estrutura está atrelada às suas práticas, dotando-as de legitimidade pela própria adoção das regras que administram algumas de suas ações - como alimentar-se de frutas, verduras, cereais, alimentos diet e light, a prática de exercícios -, por outro, ela é reelaborada pela ação da senhora, quando, por escolha própria, mediante o monitoramento do fluxo contínuo da vida social da qual faz parte, realiza atitudes diferenciadas diante dos modelos padronizados de envelhecimento.
Entre as preocupações centrais de Rita, está a organização do ambiente doméstico, especialmente para oferecer aos filhos as melhores condições possíveis para que possam estudar, alimentar-se bem e descansar. Essa é uma das justificativas que apresenta como impedimento para participar mais ativamente de grupos que integram idosos. Para Rita, os filhos, ainda que adultos, ocupam o centro de sua rotina. Mesmo sendo estimulada por algumas amigas do grupo para frequentar programações festivas, participar de viagens, entre outras atividades, Rita prioriza a vida doméstica.

Rita: Porque o sonho da gente, depois que os filhos crescem, é ver os filhos realizados. Meu sonho maior é esse, entendeu? Até mais do que viajar, do que estar de passeios. Nem se compara. Eu luto para isso, para ver o sucesso dos meus filhos. Os desejos deles são meus também, prefiro estar ao lado deles agora. Porque imagina esse menino trabalhando com coisa sem futuro? Prefiro que ele continue se preparando para coisas melhores. Invisto pra isso. Se inventarem de casar agora, como vão manter o padrão que tiveram a vida toda? Conseguem não, porque aqui pagam muito pouco.Por isso, digo direto, é a ladainha: - "Procurem o melhor. Nada de perder tempo com coisa sem futuro”.

Seus projetos apresentam forte peso relacional. Envolvem a missão materna de cuidar e ajudar aos filhos a conquistar a realização pessoal, a definição profissional e a superação das incertezas e inseguranças especialmente do mundo do trabalho, próprias da sociedade de risco (Beck, 2010). Assim como comenta Singly (2001, 2007), também para Rita o espaço privado da família deve estar sempre a serviço dos indivíduos que o compõem. No entanto, isso não quer dizer que essa senhora anula seus próprios projetos em função dos filhos. Diferentemente, sua lógica de suprir as necessidades atuais dos filhos diz respeito, sobretudo, à compreensão de que, mediante a autonomização deles, ela também alcançará maior autonomia num futuro próximo, ao menos no aspecto financeiro. Trata-se, mais uma vez, de uma ação monitorada com vistas a maiores garantias de menor exposição ao risco. Neste caso, o risco de ter de arcar com as despesas dos filhos mais tempo do que o pretendido.

Rita: - O que eu mais quero é que eles vivam a vida deles sem depender de mim. Quem gosta de viver às custas dos outros? Ninguém quer isso, não. Nem eu quero que eles vivam assim, porque eu tenho também minhas necessidades e me privo por conta deles. É curso, é roupa, é tudo comigo. O pai nunca ajudou em nada! Quando cada um tiver sua independência, pra mim vai ser um alívio. Vou estar ali, no apoio moral, junto, mas a coisa melhor do mundo é você ter sua vida, e pra isso tem que ter dinheiro. Tanto eles como 
eu pensamos assim. Só que assim... Antigamente, com 20 anos, 22 anos, a gente já trabalhava, estudava, tudo era mais fácil para conseguir emprego e tudo. Hoje não, é uma dificuldade. Meu mais velho já está com quase 30 anos e não tem nada certo. Acho que já está na hora deles decolarem. Mas ele fala: - "Mainha, tenho que fazer tal curso, para estudar para concurso". Aí fica de bico, pega um projeto aqui, outro ali. Às vezes me aborreço, porque às vezes eu penso que eles fazem corpo mole. Mas eu sei que a concorrência é grande, aí prefiro ajudar, sabe? Não porque tenho pena deles, porque sei que eles se viravam de um jeito ou de outro, eles são inteligentes, mas porque me sinto feliz, me sinto útil. Aliás, é através de mim, do meu trabalho, por meio do meu dinheiro que eles têm tudo. Eles sabem disso, sabem que precisam de mim. Sou experiente, vivida, posso orientá-los. E precisam do meu dinheiro também.

O trecho da narrativa mostra as transformações ocorridas nas condições de acesso ao trabalho entre os jovens. Rita destaca em sua fala o aumento das dificuldades quando lembra sua juventude e compara as condições de outrora com a atualidade enfrentada por seus filhos. São problemas compartilhados pela família e que demandam a ajuda dos mais velhos, financeiramente estabilizados, em relação aos mais jovens. Casos como o de Rita e seus filhos têm sido cada vez mais recorrentes no Brasil. As contribuições materiais das gerações mais velhas para as mais jovens na família colaboram para ressaltar a importância do papel dos idosos na família e na sociedade. Como se vê na realidade de Rita, do mesmo modo como observou Saad (2004) em suas pesquisas, esse contexto socioeconômico de reduzidos postos de trabalho e de maiores exigências quanto à qualificação profissional, que particularmente atingem os grupos mais jovens, também terminam por afetar as gerações mais velhas, uma vez que são elas que passam a "arcar com o ônus de se tornarem fonte de ajuda informal para os familiares" (p. 203).

A partir do caso de Rita, é possível inferir que a responsabilização prolongada com filhos adultos pode restringir as possibilidades de vivências das gerações mais velhas, uma vez que estas últimas tornam-se mais limitadas financeiramente e, sobretudo, moralmente comprometidas com seus dependentes. Todavia, até esse comprometimento pode ser compreendido como escolhas tomadas, decisões que manifestam finalidades racionalizadas. Rita, por exemplo, diz não "ter pena" de seus filhos, ou seja, a ajuda que lhes oferece, segundo ela, não decorre apenas de uma questão de compaixão ou algo do tipo. Antes, o apoio oferecido à família guarda outros elementos, por exemplo, o de demarcar, no grupo familiar, um lugar de destaque, de poder. Isso pode ser relacionado à permanência da tradicional ideia da velhice como lugar hierarquicamente superior, não somente pela estabilidade financeira, mas também pela experiência acumulada e pela capacidade de dar conselhos.

No conjunto de suas narrativas, ${ }^{6}$ Rita exaltou as transmissões intergeracionais, situando-se como herdeira de princípios ensinados por seus pais e avós e por ela assimilados em diversos momentos da vida familiar. Como atual portadora desses conhecimentos e dotada de tantas outras experiências de vida adquiridas em outras imediações sociais, ela constrói, com mais ou menos proeminência, uma imagem de si como "vivida" e experiente, e, em consequência disso, reconhece-se como responsável pelos conselhos na família. Nesse sentido, percebem-se, nas relações entre Rita e seus filhos, vínculos fortemente característicos da tradição e das lógicas do passado coletivo mais hierarquizado, a partir dos quais ela se distingue das gerações mais novas. Mas também se percebe sua capacidade de integrar-se no presente familiar, permeado pelos ideários contemporâneos, como, por exemplo, a questão do risco, mediante a parceria entre as gerações, participando da vida dos mais jovens de forma intensa, com a perspectiva de garantir sua manutenção e reprodução no segmento social do qual fazem parte.

\section{Terceira história}

Dona Rosa tinha 70 anos quando foi entrevistada. Casada pela segunda vez, morava com o esposo, com quem vivia há 18 anos, em uma casa em Bancários. É formada em Enfermagem, atuando na área como servidora pública do SUS. Sua renda estava em torno de 4.500 reais mensais. Dona Rosa possui dois filhos: um mora nos Estados Unidos, a quem visita anualmente há dez anos, e uma filha casada, que também mora em Bancários e possui dois filhos.

Ativa no grupo de idosos da Igreja Católica de Bancários, dona Rosa gosta de envolver-se com projetos de assistência social ali desenvolvidos. E, para tanto, dedica parte de seus dias à costura de enxovais de bebê. Além disso, costuma viajar em excursões com o grupo de amigas do coral daquela comunidade religiosa. Tendo em vista suas inúmeras atividades, dona Rosa confessa dedicar pouco tempo à família. Afirma que "faz o que pode", pois prioriza atividades para além daquelas voltadas à vida familiar. Nesse sentido, fica evidente o conflito intrageracional na família, surgido por suas atividades fora de casa.

Dona Rosa: Amo demais meus netos, mas não posso fazer mais do que faço. Ajudo Doriane de vez em quando com 
eles, mas tenho minhas coisas também. Se ficar com compromisso direto com eles, não faço mais nada. Não, quando ela liga precisando de uma ajuda ou outra, tudo bem, mas para ficar direto, quero não. Tem gente que pensa que a gente tá aposentado não tem o que fazer, né? Mas não é bem assim, eu tenho muita coisa para fazer. Ela diz que en fico procurando serviço, mas eu gosto, eu faço porque eu gosto. Me realizo assim. Na Igreja, é o que mais a gente aprende: se mantenha ocupado, se mantenha ocupado. Só de enxoval de bebê eu tenho seis para fazer e não encontro tempo, menina. É uma coisa de louco encontrar tempo pra tanta coisa, mas a gente sempre dá um jeito.

Em parte, suas escolhas baseiam-se profundamente nas recomendações dos líderes da igreja que integra. Entre eles, os padres, os psicólogos da Pastoral de Idosos e os auxiliares. Nas atividades da igreja, os discursos da terceira idade, muitas vezes vistos como "muito modernos" e recorrentemente confrontados com as lógicas de ação mais tradicionais, ganham mais credibilidade e tornam-se mais acessíveis por fazer parte não somente de orientações médicas, mas também por ganhar respaldo religioso.

Dona Rosa: Olhe, a gente tem que tomar conta do nosso corpo para viver melhor, para viver mais, para evitar doenças, para participar ativamente das atividades que gostamos e não somente por uma questão de estética, para desfilar por aí. Porque isso não é coisa de mulher direita. Nosso corpo, como a própria palavra de Deus fala, é o templo do Espírito Santo. Eu preciso cuidar desse templo, preciso manter uma boa imagem, pois nós, cristãos, somos a imagem de Cristo. Jesus vivia entre as pessoas, gostava de festas, de estar no meio do povo. Era um exemplo de pessoa sociável, gostava de viajar para pregar o Evangelho, e nós temos nele esse exemplo. Precisamos estar bem para cumprir tudo isso.

Temos aqui uma reinterpretação do discurso da terceira idade a partir de uma perspectiva religiosa: o corpo não mais é visto como instrumento de prazer, e sim considerado o templo do Espírito Santo. Por isso, deve ser cuidado. A vida de Cristo é tomada como exemplo de vida sociável e alegre.

Assim, lado a lado a essas sociabilidades, dona Rosa tem acesso, na igreja em que frequenta, a recursos simultaneamente simbólicos e relacionais, os quais são fundamentais para a negociação de sua identidade e para o afastamento de imagens negativas da velhice e de sua reclusão. Nesses contextos, alguns significados sobre a velhice vão sendo formulados e disseminados, associados principalmente ao período final da vida, em que valem cuidados consigo mesmo, em todos os níveis: corporal, mental, espiritual e social, com expectativas de alongar tal período, assim como de vivê-lo de forma saudável em todos esses aspectos. Esses processos dizem assim respeito a dinâmicas de construções identitárias, na medida em que se constituem em procedimentos reflexivos sobre o próprio estado de velhice em comparação com o de outras pessoas, geralmente suas amigas da mesma geração.

Dona Rosa: Ser saudável não é somente não ter doença física ou mental. Viver de forma saudável é você estar bem em todos os sentidos: mental, corporal, assim como espiritualmente falando e socialmente também. Para que eu tenha saúde literalmente, eu tenho de me preocupar com tudo isso. Por isso, é importante compreender as escrituras para ter um espírito saudável, assim como é importante cuidar do corpo e da mente. As pessoas hoje somente se preocupam em cuidar do corpo, só se preocupam com a aparência, e por dentro estão destroçadas. Depressivas, mentalmente perturbadas e espiritualmente também. Também tem pessoas que não têm amigos, são isoladas do mundo e isso causa muitos problemas. Na velhice, eu posso ser saudável dessas diversas formas. Basta você entender e fazer por onde adotar, no seu dia a dia, atitudes que contribuam para tudo isso. Ler muito, inclusive a Bíblia, cuidar da alimentação, conversar com as pessoas, sair, se distrair, ocupar a mente, tudo isso ajuda muito. Mas têm pessoas que não estão nem aí com nada, se entregam, deixam a doença chegar, parecem até que ficam esperando por ela. Eu não sou assim. Me cuido muito, me sinto bem, sou uma idosa ativa, leio, faço minhas pinturas, costuro, cuido de minhas plantas, frequento a igreja, faço minhas orações, participo das reuniões, das festividades, converso com pessoas, viajo muito. E assim, às vezes, eu vejo que estou melhor do que outras pessoas da minha idade mesmo ou até mais novas do que eu. Não que eu queira ser melhor do que ninguém, não é isso, mas é que fica visível. Se você não se amar, se você não se cuidar, você vai virar uma pessoa infeliz e tornar sua vida insuportável.

No trecho de sua narrativa, observa-se que o corpo "é a base para o julgamento sobre o status dos outros, assim como os outros constroem seus julgamentos sobre nós a partir do que dizemos e/ou fazemos" (Featherstone, 1994, p. 54). É nesse jogo de sociabilidades, reflexividades nas relações sociais, comparações e diferenciações que se avalia o próprio envelhecimento e que se percebe a construção de representações de si e dos outros, com base em atributos como mulheres combativas ou entregues, acomodadas ou dinâmicas, energéticas ou "paradonas", extrovertidas ou introspectivas, intelectualizadas ou leigas, saudáveis ou doentes, sociáveis ou reclusas, felizes ou infelizes, entre outras infinidades de qualidades que caracterizam diferentes formas de experimentar o envelhecimento e a vida.

Exemplos como o de dona Rosa podem ser encontrados na pesquisa realizada por Lins de Barros (2007), em que a autora apresenta testemunhos de mulheres idosas envolvidas com organizações religiosas. Entre essas mulheres, foi possível constatar 
expressões do tipo: "Essas coisas tomam todo meu tempo". Tais posicionamentos puderam ser verificados quando fizeram referência às diferentes atividades nas quais se envolviam na Igreja. Segundo Lins de Barros (2007), as histórias das senhoras revelavam de forma clara a força das relações sociais não familiares ou públicas, que propiciavam um caráter excepcional à velhice que enfrentavam. No caso de dona Rosa, tais relações designam, para ela, a capacidade de estabelecer atividades públicas relevantes para seu contexto social, e não somente para ela própria. Assinalam também sua possibilidade de exercer funções para além daquelas fortemente designadas às avós, o cuidado dos netos. Essa perspectiva imprime à velhice uma racionalidade diferenciada daquelas encontrados nos grupos da terceira idade em geral. Ser ativa, para dona Rosa, significa não somente estar em envolvida em lazer ou atividades físicas, mas ser ativa num contexto social relevante, como na assistência social.

\section{Velhice, reflexividade e agência: considerações finais}

Como construção social e heterogênea, as experiências da velhice podem ser reinventadas (Debert, 1999) de inúmeras formas. Aqui, procuramos pensar esses processos de reinvenção da velhice não apenas considerando as senhoras como indivíduos tão somente influenciados pelos diferentes discursos da terceira idade, do envelhecimento ativo, entre outros, que trazem em si uma comunhão de códigos culturais da velhice contemporânea. Não as apreciamos como reflexos das estruturas que agenciam a velhice, mas procuramos considerá-las como agentes (Giddens, 2003), com capacidade reflexiva para filtrar informações e fazer escolhas próprias, individualizadas.

Buscamos pensar a reinvenção da velhice e suas relações na família - a partir das histórias de dona Ana, dona Rita e dona Rosa - considerando, sobretudo, que reinventar a velhice é um reinventar de si mesmo e das relações que estabelecemos. Os relatos dessas senhoras mostraram que essas reinvenções se projetam em meio a processos de individualização que impactam fundamentalmente as relações intergeracionais. No entanto, em meio a tais relações, as senhoras vão se conduzindo em movimentos de conflitos e harmonização de interesses familiares, que evidenciam suas capacidades de "criar uma diferença", de intervir no mundo ou de abster-se disso, segundo seus próprios critérios.

Procuramos evidenciar a tônica das interrelações de códigos culturais na condução dos comportamentos das senhoras, demonstrando que a permanência de padrões tradicionais de experimentação da velhice não significa um fechamento às mudanças, e que é possível conviver com regras tidas como tradicionais e modernas ao mesmo tempo. As histórias analisadas, revelam-nos, sobretudo, que é no diálogo entre os referenciais extra e intrafamiliares, nem sempre harmônicos, que as senhoras vão se reconstruindo e conformando seus próprios modelos de vivenciar a velhice e de lidar com aqueles familiares entre os quais elaboram seu cotidiano.

processos de reprivatização do envelhecimento. São Paulo: Ed. USP/Fapesp, 1999.

A cultura adulta e juventude como valor. ANPOCS, Caxambu, 2004.

FEATHERSTONE, Mike. O curso da vida: corpo, cultura e imagens do processo de envelhecimento. In: DEBERT, Guita G. (Org.). Antropologia e velhice. Campinas: IFCH, Unicamp, 1994. (Coleção Textos Didáticos).

FEATHERSTONE, Mike; HEPWORTH, M. Envelhecimento, tecnologia e o curso da vida incorporado. In: DeBert, Guita G.; GOLdstein, D. Políticas do corpo e o curso da vida. São Paulo: Sumaré, 2000.

GIDDENS, A. A constituição da sociedade. 2. ed. São Paulo: Martins Fontes, 2003.

Para além da esquerda e da direita. São Paulo: Unesp, 1996.

. Consequências da modernidade. 1. ed. São Paulo:

DEBERT, Guita G. A reinvenção da velhice: socialização e 
Unesp, 1991.

Modernidade e identidade. Rio de Janeiro: Jorge Zahar, 2002.

HENRIQUES, Célia; FÉRES-CARNEIRO, T.; RAMOS, Elza. Ajustes entre pais e filhos adultos coabitantes: limite e transgressão. Psicologia em Estudo, Maringá, v. 16, n. 4, p. 531-539, out./dez. 2011.

LINS DE BARROS, M. Velhice ou terceira idade? Estudos Antropológicos sobre identidade, memória e política. Rio de Janeiro: FGV, 2007.

PEIXOTO, Clarice. Entre o estigma e a compaixão e os termos classificatórios: velho, velhote, idoso, terceira idade. In: LINS DE BARROS, Myriam. Velhice ou terceira idade? Estudos Antropológicos sobre identidade, memória e política. Rio de Janeiro: FGV, 2007.

SAAD, P. M. Transferência de apoio intergeracional no
Brasil e na América Latina. In: CAMARANO, A. A. (Org.). Os novos idosos brasileiros: muito além dos 60? Rio de Janeiro: IPEA, 2004. p. 169-209.

SIMÕES, Júlio Assis. A maior categoria do país: o aposentado como ator político. In: LINS DE BARROS, Myriam. Velhice ou terceira idade? Estudos Antropológicos sobre identidade, memória e política. Rio de Janeiro: FGV, 2007.

SINGLY, François. Être soi parmi lês Autres: famille et individualisation. Paris: L'Harmattan, 2001 (Tomo 1).

FGV, 2007. Sociologia da família contemporânea. Rio de Janeiro:

VELHO, Gilberto. Individualismo e cultura: notas para uma antropologia da sociedade contemporânea. Rio de Janeiro: Jorge Zahar, 2008.

VIEGAS, Suzana de M.; GOMES, Catarina A. A identidade na velhice. Porto: AMBAR, 2007.

\title{
Three stories: female age, agency and reflexivity in contexts of cohabitation intergenerational
}

\begin{abstract}
In this paper we reflect on the female age category, relating it to issues of agency and reflexivity proposed by Anthony Giddens. More precisely, we discuss possibilities of intergenerational cohabitation relatives in contexts in which there are women who face the process of becoming old. We selected life stories of three ladies, from 62 to 70 years old, who joined a group in a doctorate research in Sociology held in Federal University of Paraíba (Brazil). The research methods were participative observation and interviews involving life histories. The questions that guided the study were: how these women deal amid their family relationships, especially among sons and daughters, and grandchildren, with the possibility of engaging their daily lives? What changes in family relationships can be identified with the interference of ideologies disseminated in elderly groups such as church and public health? We become aware of these women as agents who continuously monitor the flow of information to which you have access. These women produce their experiences of aging in the dialogue between the reference of extra and intra family, making choices that sometimes excel in family life, sometimes prioritizing extra-familial relationships.
\end{abstract}

Key words: elderly female, agency, reflexivity, intra-generational relationships, intergenerational relationships.

\section{Tres historias: edad de la mujer, la agencia y la reflexividad en contextos de convivencia intergeneracional}

\section{Resumen}

En este trabajo, tratamos de reflexionar sobre la categoría edad de las mujeres, relacionándola con la agencia y reflexividad de Anthony Giddens. Más precisamente, se discuten las posibilidades de los familiares que viven juntos en contextos intergeneracionales que incluyen mujeres de edad avanzada que también participan en grupos que promocionan el envejecimiento contemporáneo. Hemos seleccionado la historia de vida de tres mujeres que formaban parte de un grupo de mujeres de edad avanzada en una investigación de doctorado en Sociología realizada en la UFPB. Estas mujeres tenían edades comprendidas entre 62 y 70 años, respectivamente. Los métodos de investigación fueron la observación participante y las entrevistas de tipo de historia de vida. Las preguntas que guiaron el estudio fueron: ¿cómo lidian estas mujeres, entre sus relaciones familiares, especialmente con hijos y nietos, con las perspectivas de las diferentes propuestas de envejecimiento con las que se involucran en su vida cotidiana? ¿Qué cambios o estancias en las relaciones familiares pueden ser identificados con la interferencia de las ideologías diseminadas en los grupos de edad avanzada por estructuras tales como la Iglesia y la salud pública? Entendemos a estas señoras como agentes y nos dimos cuenta de que, en la medida en que 
son individuos dentro de una sociedad que controla continuamente el flujo de información a la que tienen acceso, están reinventando sus experiencias de vejez en el diálogo entre las referencias extra e intrafamiliares, en ejercicio de las opciones que tanto brillan por la convivencia familiar como priorizan las relaciones extrafamiliares.

Palabras clave: edad de la mujer, agencia, reflexividad, relaciones intrageneracionales, relaciones intergeneracionales.

Data de recebimento do artigo: 9/12/2013

Data de aprovação do artigo: 6/8/2014 